\title{
Clinically unsuspected phacoanaphylaxis after extracapsular cataract extraction with intraocular lens implantation
}

\author{
MARK S MCMAHON, JAYNE S WEISS, KLAUS G RIEDEL, \\ AND DANIEL M ALBERT
}

From the David G Cogan Eye Pathology Laboratory of the Massachusetts Eye and Ear Infirmary, Harvard Medical School, Boston, Massachusetts, USA

SUMMARY We describe the histopathological findings of an enucleation specimen from a clinically undiagnosed case of phacoanaphylaxis which occurred after extracapsular cataract extraction with intraocular lens implantation. Phacoanaphylaxis, a granulomatous inflammatory response to liberated lens protein, is potentially curable by prompt removal of residual lens material. This case emphasises that the diagnosis of phacoanaphylactic endophthalmitis should be considered in any case of extracapsular cataract extraction complicated by granulomatous intraocular inflammation.

In 1919 Straub $^{1}$ discussed the possibility that liberated lenticular protein could incite uveitis. In 1922 Verhoeff and Lemoine ${ }^{2}$ introduced the term 'endophthalmitis phacoanaphylactica' for this lensinduced intraocular inflammation. Riise $^{3}$ demonstrated that phacoanaphylaxis following extracapsular cataract extraction could be dramatically arrested by prompt removal of residual lens material. We describe the histopathological findings of an enucleation specimen from a clinically undiagnosed case of phacoanaphylaxis which occurred after extracapsular cataract extraction. This case emphasises that phacoanaphylactic endophthalmitis should be suspected in any eye with persistent unexplained uveitis after extracapsular cataract extraction.

\section{Case report}

The patient was an 80-year-old female who underwent extracapsular cataract extraction in 1983 with implantation of a Simcoe anterior chamber lens. Five days postoperatively the patient had iris bombé, and laser iridotomy was performed to relieve the pupillary block. The patient continued to experience severe intraocular inflammation, suspected to be infectious endophthalmitis. This did not respond to treatment, and the eye became increasingly painful,

Correspondence to Daniel M Albert, MD, Massachusetts Eye and Ear Infirmary, 243 Charles Street, Boston, Massachusetts 02114, USA. with only light perception vision. Six weeks after cataract extraction the eye was enucleated.

\section{PATHOLOGICAL FIN DINGS}

Gross examination revealed a shrunken, distorted eye which measured $24 \mathrm{~mm}$ in antero-posterior diameter. The sclera contained foci of haemorrhage, the cornea was cloudy, and the iris was poorly visualised. On opening the eye the vitreous was seen to be replaced by a gelatinous, dark red-brown coagulum containing a $0.5 \mathrm{~cm}$ roughly oval greywhite mass involving the lens remnants (Fig. 1).

On microscopic examination the cornea was noted to contain a well-healed full-thickness scar with chronic inflammatory cells, red blood cells, and extracellular pigment granules. The basal cell layer of the epithelium was noted to be oedematous. Bowman's membrane was interrupted peripherally by a fibrovascular pannus containing chronic inflammatory cells. Descemet's membrane was fragmented at the site of the cataract incision. Endothelial cells were decreased in number and a retrocorneal membrane was present. The anterior chamber was shallow and contained chronic inflammatory cells, red blood cells, and pigment granules. The iris was infiltrated by plasma cells, lymphocytes, and epithelioid cells. The iris was adherent peripherally to the retrocorneal membrane, which closed the angle on one side. Posteriorly the iris was adherent to an inflammatory mass which enveloped residual lens 


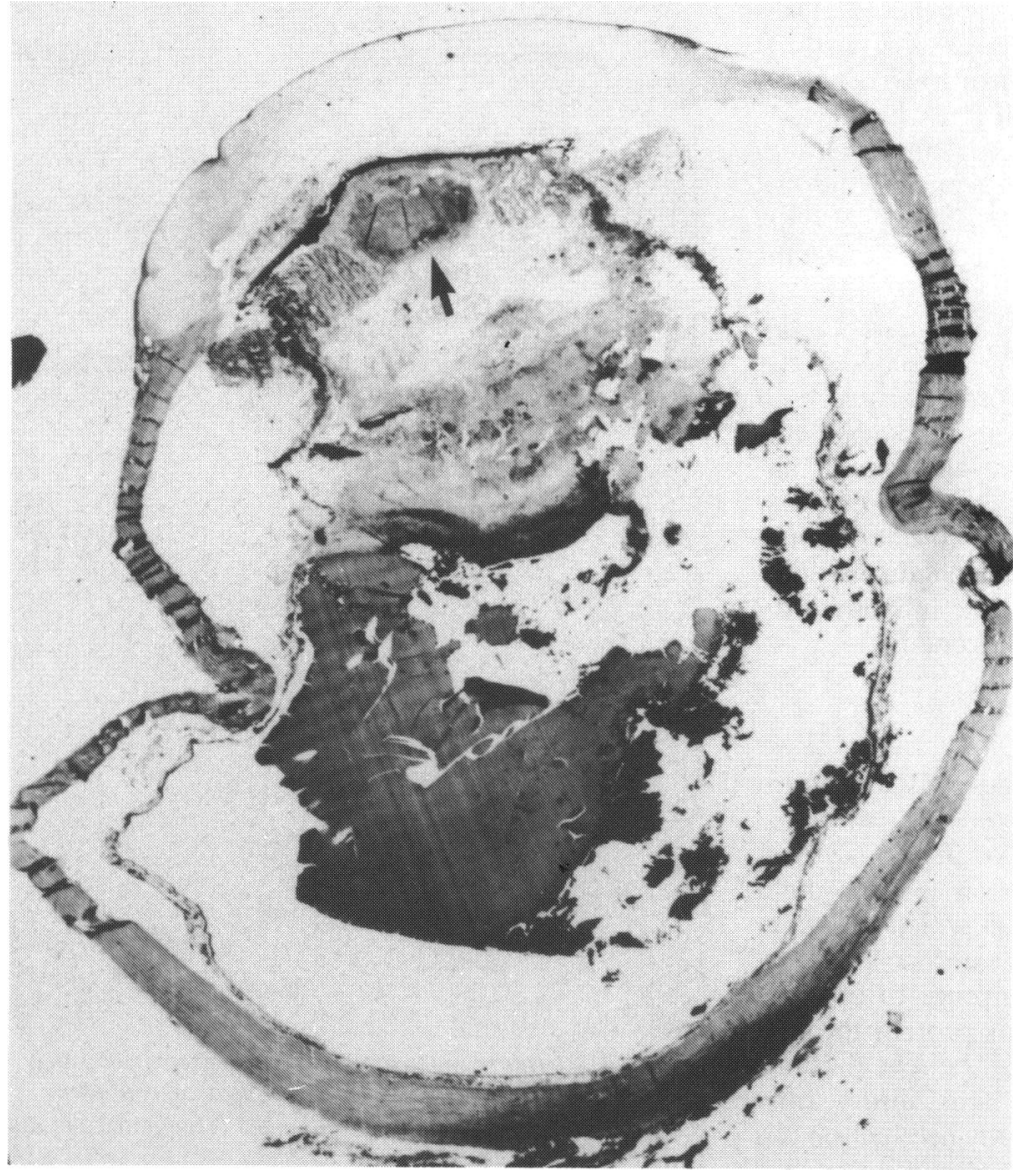

Fig. 1 Low magnification view showing phthisical eye. Inflammatory mass (arrow) can be visualised posterior to iris.

(Haematoxylin and eosin, $\times 7 \cdot 5$ ).

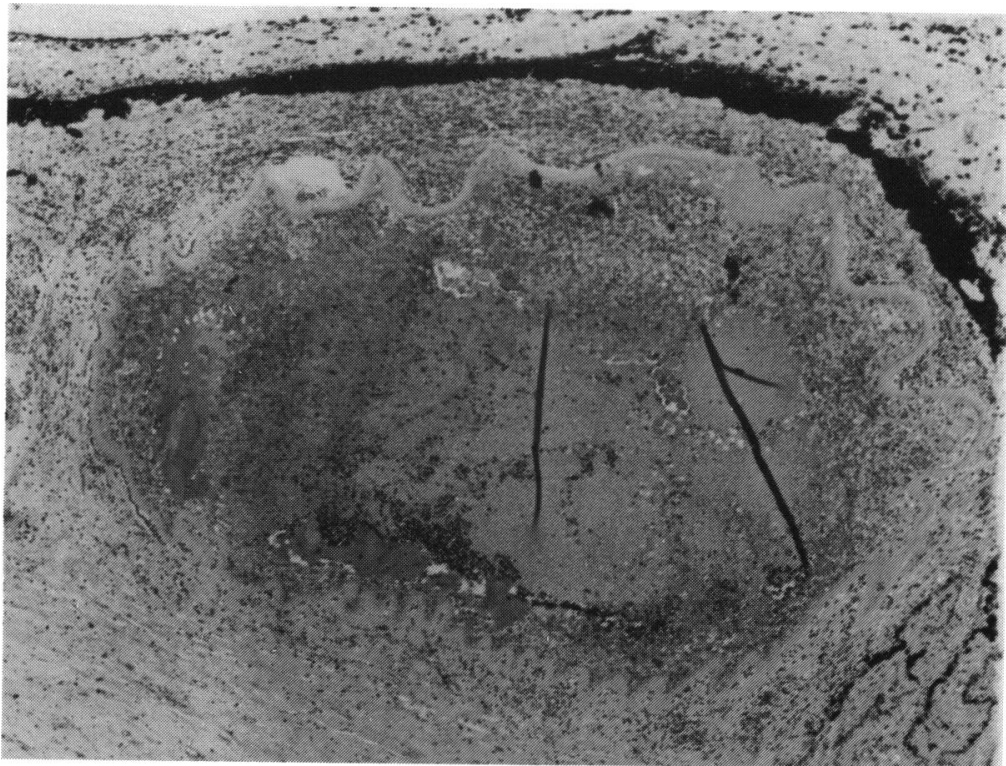

Fig. 2 Inflammatorymass containing lens capsule and liquefied lens cortex material. (Haematoxylin and eosin, $\times 28$ ). 
cortex and capsule (Figs. 2, 3). The capsule was thickened and folded. Remnants of lens cortical material demonstrated liquefaction and were infiltrated by eosinophils, polymorphonuclear leucocytes, and lymphocytes (Fig. 4). Further peripherally, epithelioid cells, giant cells, cystic spaces, and red blood cells were present (Fig. 5). The ciliary body was atrophic, hyalinised, and encased in the inflammatory mass.

The retina, which was attached in part to the inflammatory mass, was totally detached, disorganised, and atrophic. Subretinal serous fluid contained blood, non-granulomatous chronic inflammatory cells, polymorphonuclear leucocytes, pigment granules, and pigment-laden macrophages. The retinal pigment epithelium was absent in some areas. The choroid was partly detached and infiltrated by non-granulomatous chronic inflammatory cells. The sclera was folded and thickened.

\section{Discussion}

Endophthalmitis phacoanaphylactica is the term introduced by Verhoeff and Lemoine ${ }^{2}$ for the lensinduced endophthalmitis which was previously described by Straub. 'Phacoanaphylaxis is generally held to be an autoimmune phenomenon which occurs in response to the release of sequestered 'non-self' antigens, usually as a result of rupture of the lens capsule or possibly leakage of lens protein through the capsule. Marak and coworkers ${ }^{45}$ believe that this concept does not explain why lens injury only irregularly leads to antilens antibody production nor why phacoanaphylactic endophthalmitis is such a rare disease. They contend that $\mathrm{T}$ cell tolerance is normally maintained by small amounts of circulating lens protein and that the pathogenesis of phacoanaphylaxis involves reversal of acquired tolerance at the T cell level. This tolerance may be altered by trauma, possibly through the adjuvant effect of wound contamination. ${ }^{6}$

Clinically the onset can occur as early as 1 to 14 days after leakage of lens material, and is manifest by granulomatous uveitis in the injured eye centred around the region of the lens. The inflammation may develop insidiously or acutely with congestion, a hazy cornea, white keratic precipitates, and an intense cellular exudation into the anterior chamber. ${ }^{7}$

The clinical diagnosis of phacoanaphylaxis, particularly in an eye with an intraocular lens implant, is difficult, and on routine examination the condition may be indistinguishable from granulomatous uveitis of other causes, or endophthalmitis. The fact that the inflammation is centred round the lens may be detected by ultrasound. Paracentesis typically reveals evidence of chronic granulomatous inflam-

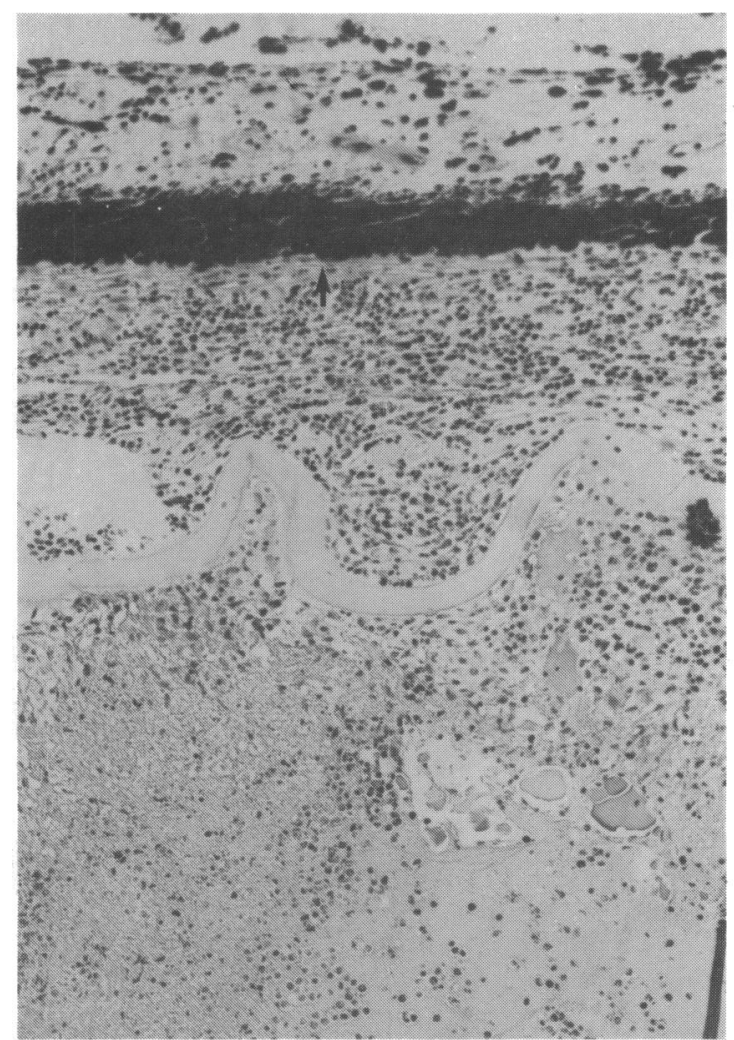

Fig. 3 The iris (arrow) is shown to be adherent posteriorly to the inflammatory mass. The iris is infiltrated by plasma cells, lymphocytes, and epithelioid cells. (Haematoxylin and eosin, $\times 80$ ).

mation rather than the acute inflammation of bacterial endophthalmitis. It should be kept in mind, however, that fungal endophthalmitis can cause granulomatous inflammation. A high index of suspicion for phacoanaphylaxis in eyes with residual lens material and granulomatous inflammation is advised. Should such an eye. not respond to steroid and/or antibiotic treatment, prompt removal of the residual lens would be necessary for definitive diagnosis and treatment.

Histopathologically the inflammatory reaction in phacoanaphylaxis is centred round the damaged lens, which is extensively infiltrated by polymorphonuclear leucocytes and eosinophils. Surrounding the lens is a zone of epithelioid and giant cells. The adjacent iris and ciliary body are inflamed and infiltrated with lymphocytes and plasma cells. ${ }^{?}$

The clinician must be able to differentiate phacoanphylaxis from other complications of cataract surgery such as phacolytic glaucoma, sympathetic ophthalmia, or endophthalmitis. In phacolytic 


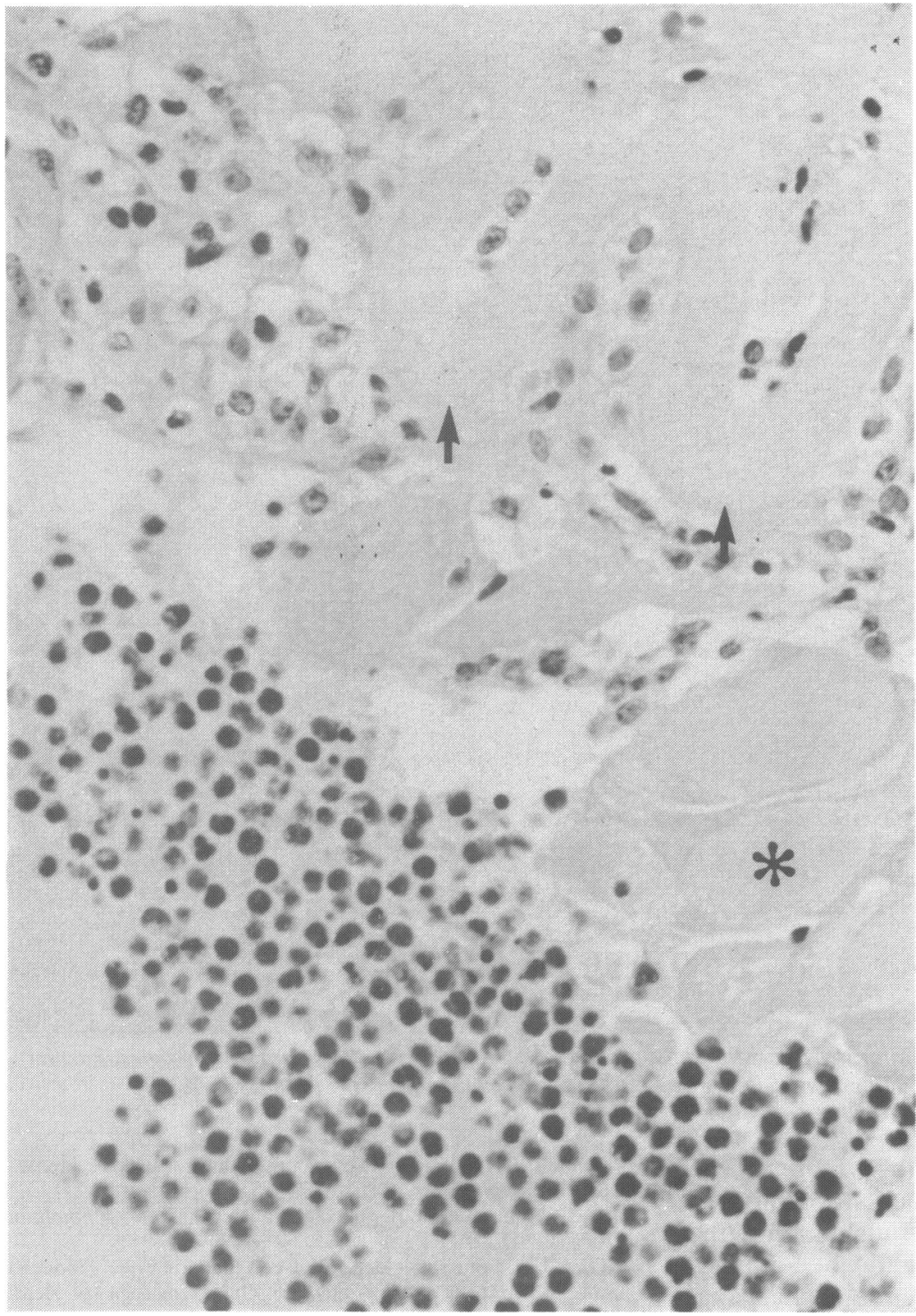

Fig. 4 High magnification of acute inflammatory reaction around folded lens capsule (arrows) and liquefied lens cortex material (asterisk). (Haematoxylin and eosin, $\times 200)$.

glaucoma, macrophages engorged with lens material become lodged in the trabecular meshwork. The clinical picture consists of a severe increase of intraocular pressure with cells in the anterior chamber. Keratic precipitates and posterior synechiae, often seen with phacoanaphylaxis, are typically absent. Sympathetic ophthalmia is a bilateral, granulomatous panuveitis which usually occurs two weeks ${ }^{8}$ or more after accidental or iatrogenic injury. The injured eye appears irritated and injected shortly after surgery, culminating in a picture of persistent bilateral uveitis characterised by 'mutton fat' keratic precipitates, iris and pupillary nodules, posterior synechiae, and the appearance of yellow-white Dalen-Fuchs nodules in the periphery of the fundus. Approximately one-fourth of phakic eyes enucleated for sympathetic ophthalmia show evidence of phacoanaphylaxis." The signs and symptoms of bacterial endophthalmitis are generally present $18-72$ hours after surgery and include increasing pain, hyperaemia, chemosis, lid and corneal oedema, anterior chamber and vitreous inflammation, and a decreased or absent retinal reflex.

If phacoanaphylaxis is left untreated, an unremitting downhill course of chronic inflammation may ensue, ultimately leading to synechiae, cyclitic mem- 


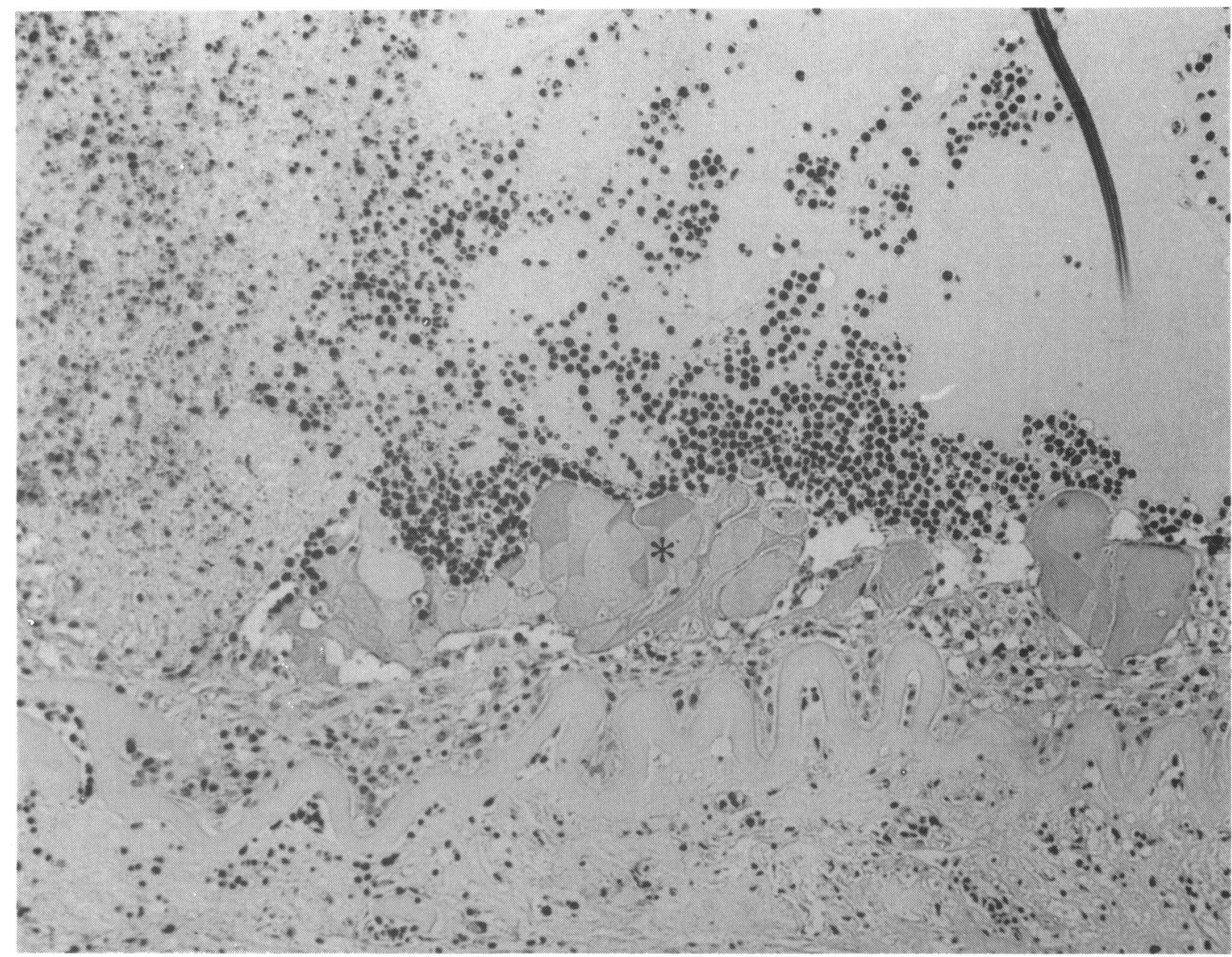

Fig. 5 Liquefied lens cortex (asterisk) infiltrated by eosinophils, polymorphonuclear leucocytes, and lymphocytes. Further peripherally, chronic granulomatous inflammatory cells are present. (Haematoxylin and eosin, $\times 100$ ).

brane, retinal detachment, and phthisis bulbi. In any case of extracapsular cataract extraction complicated by a granulomatous intraocular inflammation the diagnosis of phacoanaphylaxis should be seriously considered. The ability to differentiate phacoanaphylaxis from phacolytic glaucoma," sympathetic ophthalmia," or endophthalmitis has important therapeutic implications.

The present report is to the best of our knowledge the first case occurring after an intraocular lens implant. Since the majority of these procedures are at present performed with extracapsular extractions, lens cortex may be left in the eye. The occurrence of phacoanaphylaxis is therefore not surprising and must be considered in this type of surgery.

\section{References}

1 Straub M. On inflammation of the eye caused by resorption of crystalline lens matter in eye lymph. Amsterdam: de Bussy, 1919.
2 Verhoeff FH, Lemoine AN. Endophthalmitis phacoanaphylactica. Am J Ophthalmol 1922; 5: 737-45.

3 Riise P. Endophthalmitis phacoanaphylactica. Am J Ophthalmol 1965; 60: 911-5.

4 Marak GE, Font RA, Alepa P. T-cell function in lens-induced endophthalmitis. XXIII Concilium Ophthalmologicum Acta, Part II. Kyoto, 1978: 950.

5 Marak GE, Font RA, Weigle WO. Pathogenesis of lens-induced endophthalmitis. In: Silverstein AM, O'Connor GR, eds. Immunology and immunopathology of the eye. Paris: Masson, 1979: 135.

6 Schlaegel TF, O'Connor GR. Hypersensitivity uveitis. In: Duane TD, ed. Clinical ophthalmology. Philadelphia: Harper and Row, 1982: 45.

7 Hogan MJ, Zimmerman LE. Ophthalmic pathology. 2nd ed. Philadelphia: Saunders, 1962: 155.

8 Lubin JR, Albert DM, Weinstein M. Sixty-five years of sympathetic ophthalmia: a clinicopathologic review of 105 cases (19131978). Ophthalmology (Rochester) 1980; 87: 109-21.

9 Blodi FC. Sympathetic uveitis as an allergic phenomenon. Ophthalmology (Rochester) 1959; 63: 642.

10 Jaffe NS. Cataract surgery and its complications. St Louis: Mosby, 1981.

11 Easom HA, Zimmerman LE. Sympathetic ophthalmia and bilateral phacoanaphylaxis. Arch Ophthalmol 1964; 72: 9-15. 